\title{
Application of Silica-Supported Alkylating Reagents in a One-Pot, Sequential Protocol to Diverse Benzoxathiazepine 1,1-Dioxides
}

Saqib Faisal, Pradip K. Maity, Qin Zang, Thiwanka B. Samarakoon, Robert L. Sourk, and Paul R. Hanson*

Department of Chemistry, University of Kansas, 1251 Wescoe Hall Drive, Lawrence, Kansas 66045-7582, United States

The University of Kansas Center for Chemical Methodologies and Library Development (KU-CMLD), 2034-Becker Drive, Delbert M. Shankel Structural Biology Center, Lawrence, Kansas 66047, United States

Supporting Information

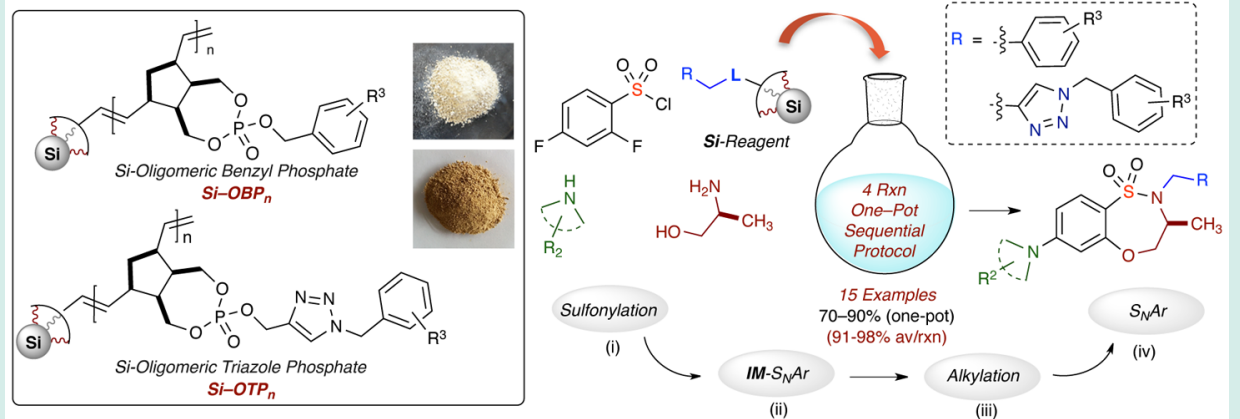

ABSTRACT: Applications of silica-ROMP reagents in a one-pot, sequential protocol have been developed for the synthesis of a variety of diverse benzoxathiazepine 1,1-dioxides. This protocol includes sulfonylation, intramolecular $S_{N} A r$, alkylation with silicasupported oligomeric benzyl $\left(\mathrm{Si}-\mathrm{OBP}_{n}\right)$ and triazole $\left(\mathrm{Si}-\mathrm{OTP}_{n}\right)$ phosphates, and intermolecular $\mathrm{S}_{\mathrm{N}} \mathrm{Ar}$ addition with a number of secondary amines in one-pot to afford a variety of unique benzoxathiazepine 1,1-dioxides sultams in good to excellent yields.

KEYWORDS: one-pot, Si-immobilized reagents, alkylation, $S_{N} A r$, benzoxathiazepine 1,1-dioxides

M ulticomponent reactions in one-pot processes are efficient pathways to synthesize complex heterocyclic scaffolds from simple building blocks. ${ }^{1}$ One-pot strategies enable the formation of multiple bonds and stereocenters in one synthetic step, as well as reducing purification resources, time and waste. This process minimizes the need of workup and procedures for chromatographic separations of intermediary reactions. Among several literature reports, elegant efficient efforts by Hayashi ${ }^{2}$ have demonstrated the power of consecutive one-pot, sequential procedures to complete multistep syntheses.

The utilization of immobilized reagents in one-pot protocols can further integrate synthesis, diversification, and purification into one parallel process to rapidly expand efforts in early stage drug discovery. ${ }^{3}$ A number of technologies for immobilization of reagents and catalysts have been developed, including those based on polystyrene resins, ${ }^{4}$ Janda-gels and microporous resins, ${ }^{5}$ soluble polyethylene glycol (PEG) polymers, ${ }^{6}$ monolith, ${ }^{7}$ fluorous-tagging, ${ }^{8}$ and silica. ${ }^{9}$ In particular, silicasupported reagents and scavengers have shown a number of advantages that can exploited in synthesis, including (i) elimination of the precipitation step, (ii) avoidance of polymeric swelling, and (iii) providing a free-flowing solid support for ease of handling. These features have inspired the recent development of a number of silica-supported reagents and catalysts. ${ }^{10} \mathrm{~A}$ critical part of developing successful silica- supported reagents and scavengers is finding a suitable technology to install functional groups on the surface of silica. The use of ring-opening metathesis polymerization (ROMP) to attach functional groups on $\mathrm{Nb}$-tagged silica core, has proven to be an efficient method for high-load functionality on costeffective and environmentally benign silica particles. ${ }^{11} \mathrm{~A}$ number of ROMP-derived Si-supported reagents have been developed in our group. ${ }^{12}$ To expand the applicability of our recently developed silica-immobilized benzyl phosphate Si$\mathrm{OBP}_{n}$ and triazole phosphate $\mathrm{Si}-\mathrm{OTP}_{n}$ reagents, ${ }^{13,14}$ we herein report studies aimed at the use of Si-OBP ${ }_{n}$ and Si-OTP ${ }_{n}$ in onepot, sequential protocols for the facile synthesis of diverse benzothiaoxazepine-1,1-dioxides.

Benzothiaoxazepine-1,1-dioxides are unique scaffolds, ${ }^{15}$ that have shown a broad range of bioactivities, including inhibition against a variety of enzymes. ${ }^{16}$ Substituted benzothiaoxazepine1,1-dioxides have shown activity as antipsychotic agents, ${ }^{17}$ modulators of histamine $\mathrm{H}_{3}$-recceptor, ${ }^{18}$ glucokinase activators, ${ }^{19}$ and modulators of AMPA receptors (Figure 1 ). ${ }^{20}$ The current demand is to develop step-economical methods, which can facilitate the synthesis of these biologically inspired sultams in a desirable fashion. In light of our recent approaches for the

Received: March 23, 2016

Revised: $\quad$ May 11, 2016

Published: June 14, 2016 

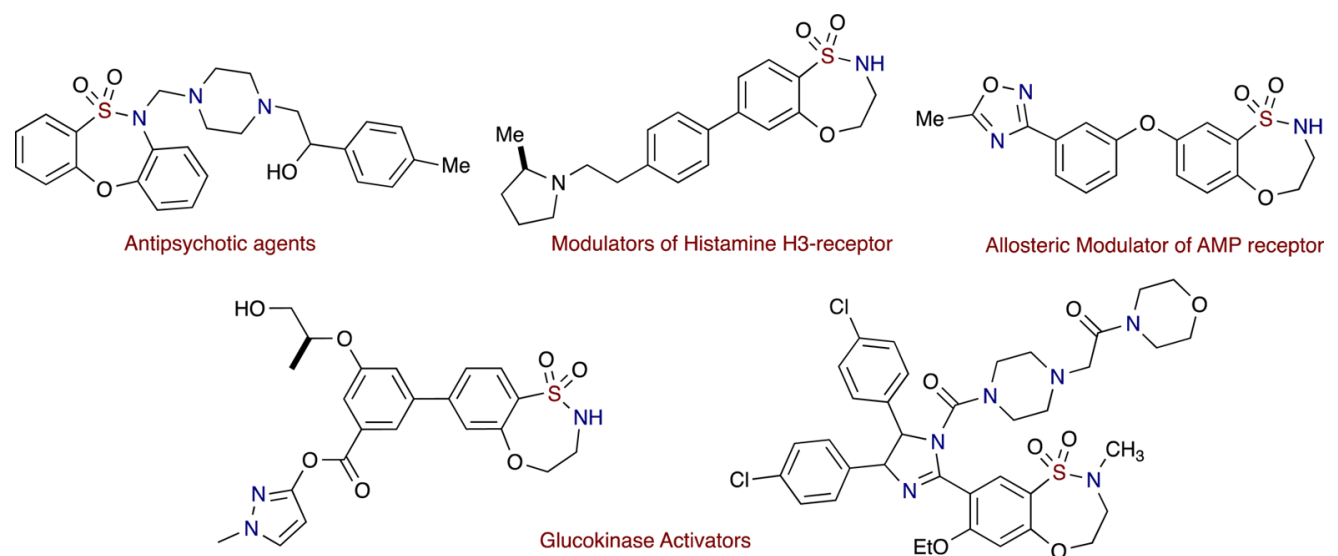

Glucokinase Activators

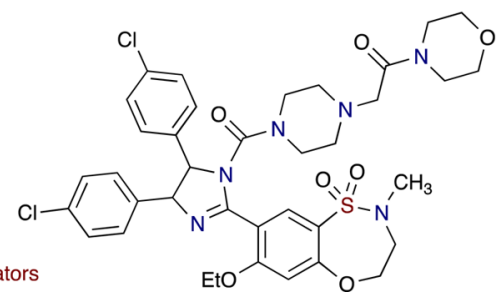

Figure 1. Biologically active benzothiaoxazepine-1,1-dioxide-containing sultams.

Scheme 1. Synthesis of Si-Supported Oligomeric Benzyl ( Si-OBP $\left._{n}\right)$ and Triazole (Si-OTP ${ }_{n}$ ) Phosphates
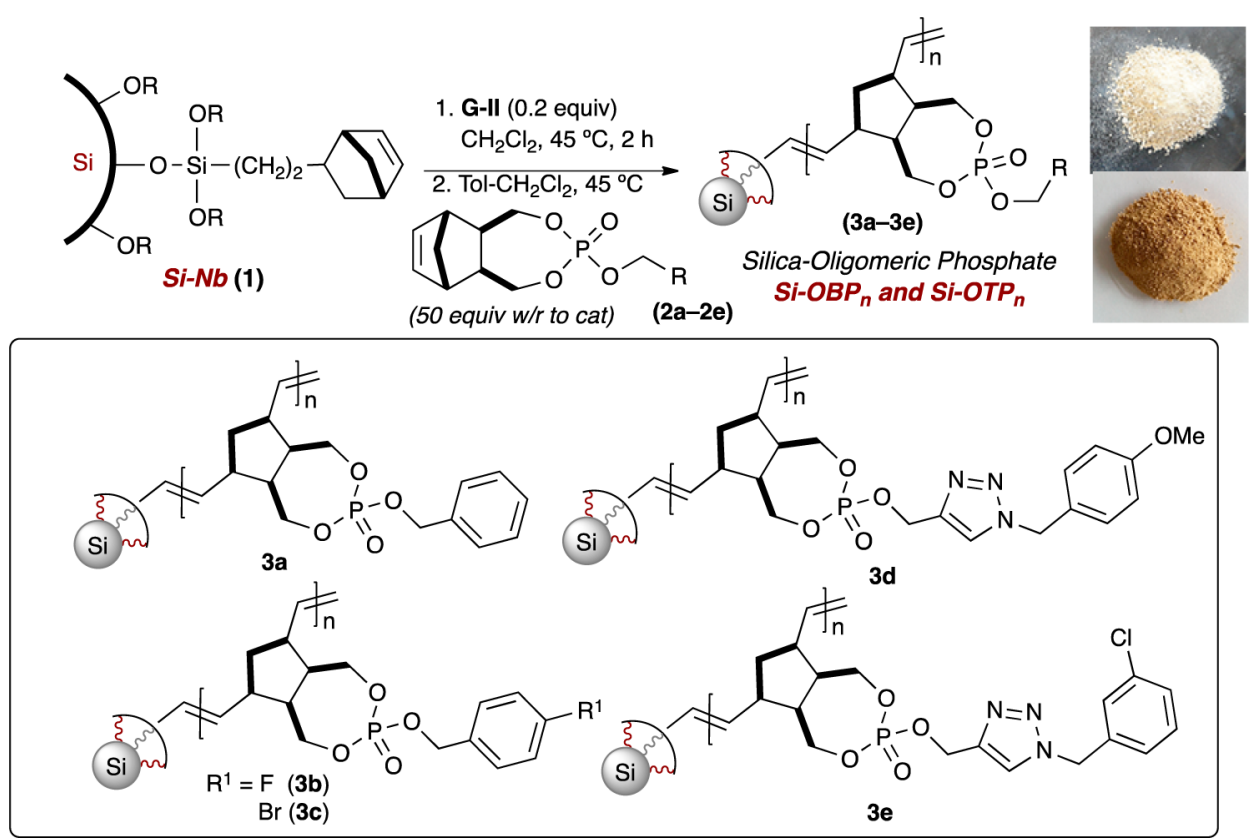

Scheme 2. Synthesis of Benzothiaoxazepine-1,1-dioxides in a One-Pot, Sequential Protocol

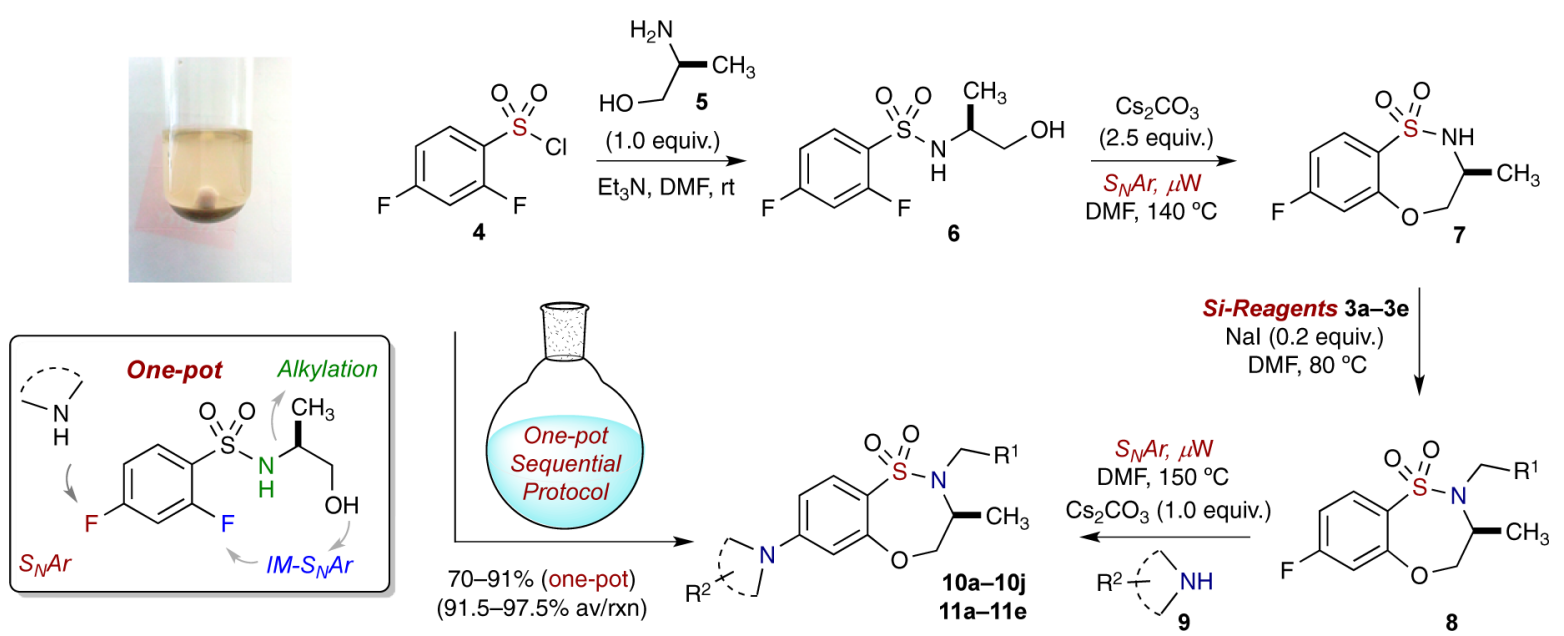

synthesis of scaffolds containing benzothiaoxazepine-1,1dioxides, ${ }^{21}$ herein, we further elaborate the importance of 2,4- difluoroarylsulfonyl chloride (4) as an attractive building block for the generation of these scaffolds. 
Table 1. One-Pot Synthesis of Benzothiaoxazepine-1,1-dioxides Utilizing Various Si-OBP Reagents
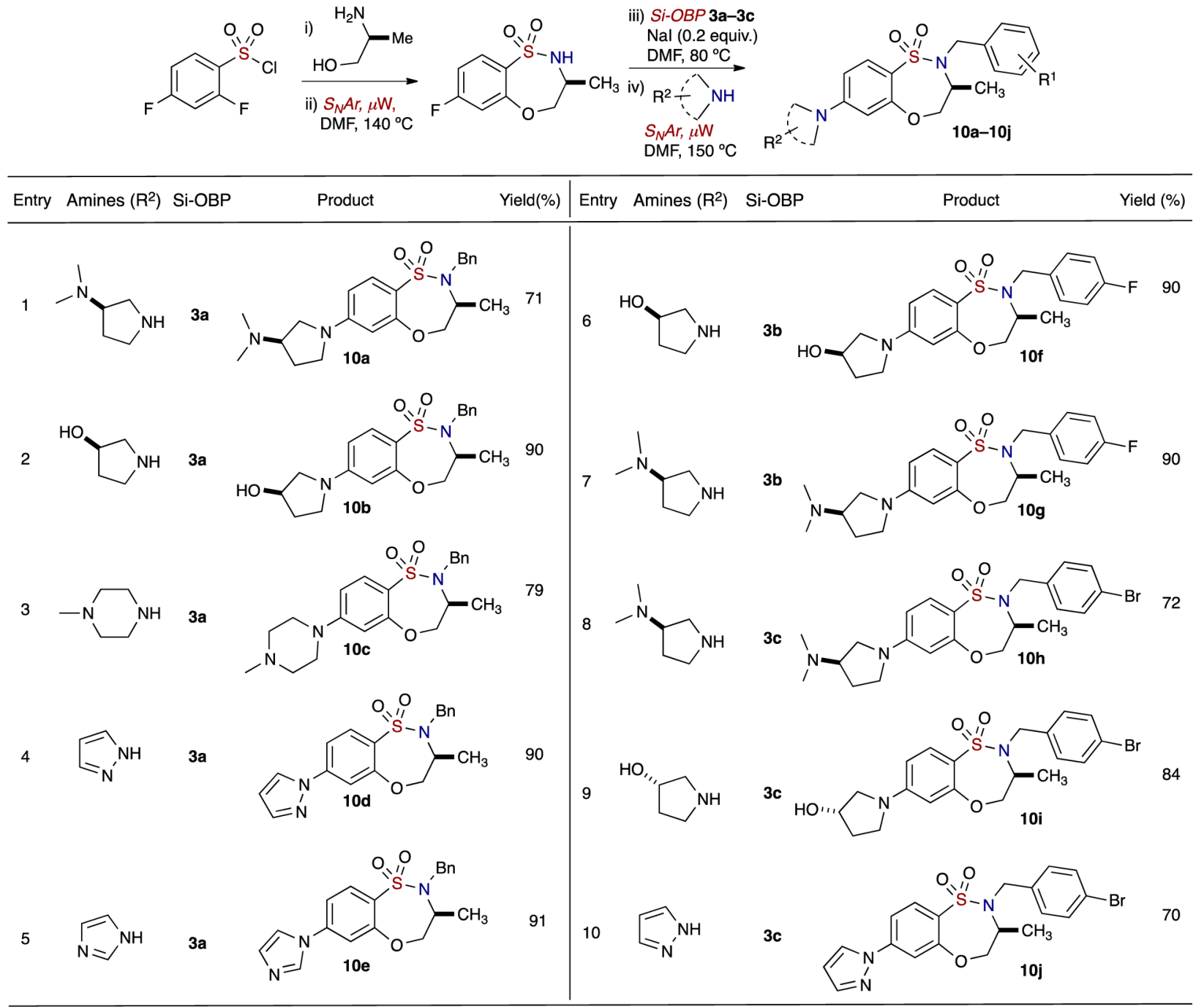

The titled silica phosphate reagents, $\mathrm{Si}-\mathrm{OBP}_{n}$ and $\mathrm{Si}-\mathrm{OTP}_{n}$ were synthesized from norbornenyl-functionalized silica $(\mathrm{Si}-$ $\mathrm{Nb}) \mathbf{1}$ and Nb-tagged phosphate monomers $2 \mathrm{a}-2 \mathrm{e}$ using a similar protocol reported in our previous work. ${ }^{12}$ Surfaceinitiated polymerization of these monomers onto the surface of silica was achieved using the Grubbs second-generation catalyst (G-II) in toluene- $\mathrm{CH}_{2} \mathrm{Cl}_{2}{ }^{22}$ Following the reported procedure, the desired Si-ROMP benzylating Si-OBP ${ }_{n} 3 \mathbf{a}-3 \mathbf{c}(n \approx 50)$ and triazolating $\mathrm{Si}_{-} \mathrm{OTP}_{n} 3 \mathbf{d}-3 \mathbf{e}(n \approx 50)$ reagents were furnished as free-flowing solids on gram-scale.

With $\mathrm{Si}_{-} \mathrm{OBP}_{n}$ reagents $3 \mathrm{a}-\mathbf{3 c}$ and (triazolyl)methylating reagents $\mathrm{Si}-\mathrm{OTP}_{n} \mathbf{3 d}-\mathbf{3 e}$ in hand, we directed our attention for their utilization in the titled one-pot sequential process. Thus, we planned to achieve sulfonylation, intramolecular nucleophilic aromatic substitution (IM- $\left.\mathrm{S}_{\mathrm{N}} \mathrm{Ar}\right)$, alkylation $\left(\mathrm{Si}-\mathrm{OBP}_{n}\right.$ and $\mathrm{Si}-\mathrm{OTP}_{n}$ ) and intermolecular $\mathrm{S}_{\mathrm{N}} \mathrm{Ar}$ reactions using the same solvent (DMF) in an overall one-pot protocol. The synthesis started with commercially available 2,4-difluorobenzenesulfonyl chloride (4), and a simple chiral amino alcohol 5 to achieve sulfonylation at room temperature using $\mathrm{Et}_{3} \mathrm{~N}$ in DMF. The resulting sulfonamide 6 next underwent facile IM$\mathrm{S}_{\mathrm{N}} \mathrm{Ar}$ cyclization using microwave conditions at $140{ }^{\circ} \mathrm{C}$ in the same pot to furnish benzothiaoxazepine-1,1-dioxide 7 (Scheme 2). Further diversification of 7 was achieved through use of Si-
$\mathrm{OBP}_{\mathrm{n}}$ and $\mathrm{Si}-\mathrm{OTP}_{\mathrm{n}}$ for benzylation and (triazolyl)methylation, respectively. Successful benzylations using $\mathrm{Si}^{-} \mathrm{OBP}_{\mathrm{n}} 3 \mathbf{3 a}$ of the corresponding cyclic sulfonamides were achieved in the same pot by heating the reaction mixture to $80^{\circ} \mathrm{C}$ for $10-12 \mathrm{~h}$. The final intermolecular $S_{N} A r$ reaction $\left(150{ }^{\circ} \mathrm{C}\right.$ under microwave irradiation) with a variety of cyclic five- or six-membered secondary/aromatic amines afforded diverse benzofused sulfonamides 10a-10e in the same pot (Table 1, entry 1-5).

In the next stage, different variants of silica-immobilized benzylating reagents $3 \mathbf{b}-\mathbf{3} \mathbf{c}$ were employed in similar one-pot procedures, and the desired $N$-benyzlated benzoxathiazepine 1,1-dioxides $10 \mathrm{f}-10 \mathrm{j}$ were achieved after the final intermolecular $S_{N} A r$ reactions (DMF, $150{ }^{\circ} \mathrm{C}$ under microwave irradiation), again using a variety of cyclic five-membered secondary/aromatic amines (Table 1, entry 6-10).

We next studied diversifications via sulfonamide $N$ (triazolyl)methylation utilizing $\mathrm{Si}-\mathrm{OTP}$ reagents $\mathbf{3 d - 3 e}$ as summarized in Table 2. These efforts were driven by the biological importance of 1,2,3-triazole-containing scaffolds, ${ }^{23}$ as well as their effective mimicry of trans-amide bonds due to similarity in size, planarity, dipole and H-bonding capabilities. ${ }^{24}$ To consider the biological importance of benzoxathiazepine 1,1-dioxides, we planned to design a small library of diverse $\mathrm{N}$ (triazolyl)methylated benzoxathiazepine 1,1-dioxides deriva- 
Table 2. One-Pot Synthesis of Benzofused Sultams Utilizing Variable Si-OTP Reagents

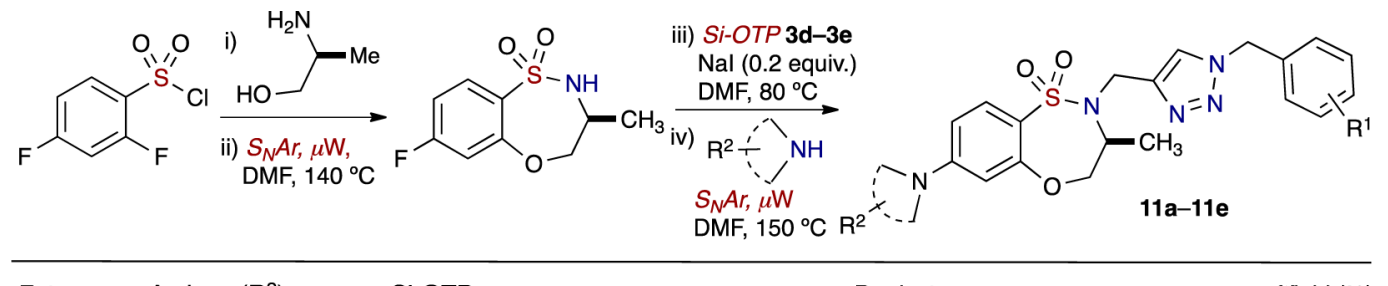

\begin{tabular}{|c|c|c|c|c|}
\hline Entry & Amines $\left(\mathrm{R}^{2}\right)$ & Si-OTP & Product & Yield (\%) \\
\hline
\end{tabular}

1<smiles>O[C@H]1CCNC1</smiles>

2<smiles>CN(C)[C@H]1CCNC1</smiles>

3<smiles>c1cn[nH]c1</smiles>

4<smiles>c1ccc(CC2CCNCC2)cc1</smiles>

5

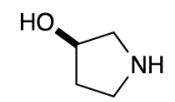

3d

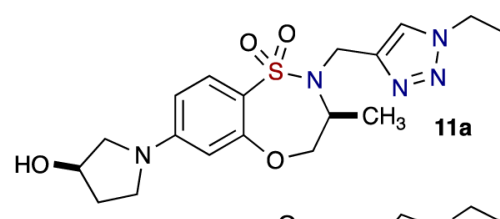

$3 d$

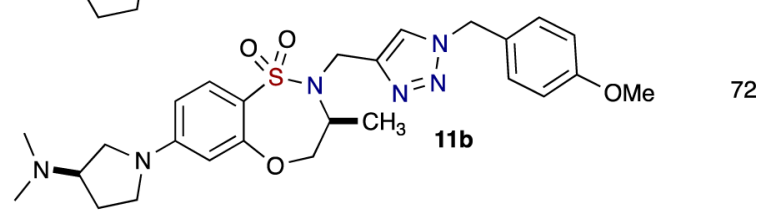<smiles>COc1ccc(Cn2cc(CN3[C@@H](C)COc4cc(-n5cccn5)ccc4S3(=O)=O)nn2)cc1</smiles><smiles>C/C=N\CC</smiles>

tives using a similar one-pot protocol as described above. ${ }^{25}$ Subsequent intermolecular $S_{N} A r$ reaction in the same pot using various cyclic amines afforded the desired $\mathrm{N}$-(triazolyl)methylated benzoxathiazepine 1,1-dioxides 11a-11e in high yield, 70-92\% over four sequential steps, representing average yields of $91.5-98 \%$ per reaction (av/rxn) (Table 2).

The one-pot, sequential protocol employing Si-alkylating reagents $3 \mathbf{a}-\mathbf{3} \mathbf{e}$ highlights the importance of our recently developed silica-immobilized reagents, which allow for facile direct $N$-benzylation or $N$-(triazolyl)methylation. Overall, grafting of $\mathrm{Nb}$-tagged silica particles with functionalized $\mathrm{Nb}$ tagged phosphate monomers using ROM polymerization efficiently yields high-load, hybrid Si-immobilized oligomeric benzyl $\left(\mathrm{Si}-\mathrm{OBP}_{n}\right)$ and triazole phosphates $\left(\mathrm{Si}-\mathrm{OTP}_{n}\right)$. We have now demonstrated applications of these Si-ROMP reagents in the diversification of core scaffolds to achieve the synthesis of a variety of unique benzoxathiazepine 1,1-dioxides in a one-pot, sequential protocol. Efforts to expand the scope of these reagents to various drug-related molecules, and improvement in synthesis and scale-up are continued for application in diversityoriented synthesis.

\section{ASSOCIATED CONTENT}

\section{S Supporting Information}

The Supporting Information is available free of charge on the ACS Publications website at DOI: 10.1021/acscombsci.6b00041.

Experimental details and NMR spectral data for new compounds (PDF)

\section{AUTHOR INFORMATION}

\section{Corresponding Author}

*E-mail: phanson@ku.edu.

\section{Notes}

The authors declare the following competing financial interest(s): P.R.H. is on the Scientific Advisory Board of Materia, Inc.

\section{ACKNOWLEDGMENTS}

This research was made possible by the National Institute of General Medical Sciences (NIH STTR R42GM097896) and NIH Center for Chemical Methodologies and Library Development at the University of Kansas (P50 GM069663). We thank Materia, Inc., for providing the metathesis catalyst. 
The authors thank Justin Douglas and Sarah Neuenswander in the University of Kansas NMR Laboratory.

\section{REFERENCES}

(1) For excellent reviews on this topic, see: (a) Dömling, A.; Wang, W.; Wang, K. Chemistry and Biology of Multicomponent Reactions. Chem. Rev. 2012, 112, 3083-3135. (b) Malinakova, H. C. Recent advances in the discovery and design of multicomponent reactions for the generation of small-molecule libraries. Reports in Organic Chemistry 2015, 5, 75-90. (c) Rotstein, B. H.; Zaretsky, S.; Rai, V.; Yudin, A. K. Small Heterocycles in Multicomponent Reactions. Chem. Rev. 2014, 114, 8323-8359. (d) Hong, B.-C.; Raja, A.; Sheth, V. M. Asymmetric Synthesis of Natural Products and Medicinal Drugs through One-PotReaction Strategies. Synthesis 2015, 47, 3257-3285. (e) Armstrong, R. M.; Combs, A. P.; Tempest, P. A.; Brown, S. D.; Keating, T. A. Multiple-Component Condensation Strategies for Combinatorial Library Synthesis. Acc. Chem. Res. 1996, 29, 123-131.

(2) (a) Hayashi, Y. Pot economy and one-pot synthesis. Chem. Sci. 2016, 7, 866-880. (b) Ishikawa, H.; Suzuki, T.; Hayashi, Y. Highyielding synthesis of the anti-influenza neuramidase inhibitor (-)-oseltamivir by three "One-Pot" operations. Angew. Chem., Int. Ed. 2009, 48, 1304-1307. (c) Ishikawa, H.; Suzuki, T.; Orita, H.; Uchimaru, T.; Hayashi, Y. High-Yielding Synthesis of the AntiInfluenza Neuraminidase Inhibitor (-)-Oseltamivir by Two "OnePot" Sequences. Chem. - Eur. J. 2010, 16, 12616-12626.

(3) (a) Booth, R. J.; Hodges, J. C. Solid-Supported Reagent Strategies for Rapid Purification of Combinatorial Synthesis Products. Acc. Chem. Res. 1999, 32, 18-26. (b) Kirschning, A.; Monenschein, H.; Wittenberg, R. Functionalized polymers-emerging versatile tools for solution-phase chemistry and automated parallel synthesis. Angew. Chem., Int. Ed. 2001, 40, 650-679. (c) Eames, J.; Watkinson, M. Polymeric scavenger reagents in organic synthesis. Eur. J. Org. Chem. 2001, 2001, 1213-1224. (d) Strohmeier, G. A.; Kappe, C. O. Combinatorial Synthesis of Functionalized 1,3-Thiazine Libraries Using a Combined Polymer-Supported Reagent/Catch-and-Release Strategy. Angew. Chem., Int. Ed. 2004, 43, 621-624. (e) Parlow, J. J.; Naing, W.; South, M. S.; Flynn, D. L. In Situ Chemical Tagging: Tetrafluorophthalic anhydrideas a "Sequestration Enabling Reagent" (SER) in the Purification of Solution Phase Combinatorial Libraries. Tetrahedron Lett. 1997, 38, 7959-7963. (f) Miller, A. L., II; Bowden, N. B. A Materials Approach to the Dual Site-Isolation of Catalysts Bonded to Linear Polymers and Small, Ionic Molecules for Use in One-Pot Cascade Reactions. Adv. Mater. 2008, 20, 4195-4199.

(4) (a) Lu, J.; Toy, P. H. Organic Polymer Supports for Synthesis and for Reagent and Catalyst Immobilization. Chem. Rev. 2009, 109, 815-838. (b) Storer, R. I.; Takemoto, T.; Jackson, P. S.; Brown, D. S.; Baxendale, I. R.; Ley, S. V. Multi-Step Application of Immobilized Reagents and Scavengers: A Total Synthesis of Epothilone C. Chem. Eur. J. 2004, 10, 2529-2547. (c) Baxendale, I. R.; Ley, S. V.; Piutti, C. Total Synthesis of the Amaryllidaceae Alkaloid (+)-Plicamine and Its Unnatural Enantiomer by Using Solid-Supported Reagents and Scavengers in a Multistep Sequence of Reactions. Angew. Chem., Int. Ed. 2002, 41, 2194-2197. (d) Roller, S.; Türk, H.; Stumbé, J.-F.; Rapp, W.; Haag, R. Polystyrene-graft-Polyglycerol Resins: A New Type of High-Loading Hybrid Support for Organic Synthesis. J. Comb. Chem. 2006, 8, 350-354.

(5) (a) Toy, P. H.; Janda, K. D. Soluble Polymer-Supported Organic Synthesis. Acc. Chem. Res. 2000, 33, 546-554. (b) Dickerson, T. J.; Reed, N. N.; Janda, K. D. Soluble Polymers as Scaffolds for Recoverable Catalysts and Reagents. Chem. Rev. 2002, 102, 33253344. (c) Bergbreiter, D. E. Using Soluble Polymers To Recover Catalysts and Ligands. Chem. Rev. 2002, 102, 3345-3384. (d) Bergbreiter, D. E.; Tian, J.; Hongfa, C. Using Soluble Polymer Supports To Facilitate Homogeneous Catalysis. Chem. Rev. 2009, 109, $530-582$.

(6) (a) Gooding, O. W.; Baudart, S.; Deegan, T. L.; Heisler, K.; Labadie, J. W.; Newcomb, W. S.; Porco, J. A., Jr.; van Eikeren, P. On the Development of New Poly(styrene-oxyethylene) Graft Copolymer Resin Supports for Solid-Phase Organic Synthesis. J. Comb. Chem.
1999, 1, 113-122. (b) Lee, J. W.; Fuchs, P. L. Axially Chiral Amidinium Ions as Inducers of Enantioselectivity in Diels-Alder Reactions. Org. Lett. 1999, 1, 179-181. (c) Kalinina, I.; Worsley, K.; Lugo, C.; Mandal, S.; Bekyarova, E.; Haddon, R. C. Synthesis, Dispersion, and Viscosity of Poly(ethylene glycol)-Functionalized Water-Soluble Single-Walled Carbon Nanotubes. Chem. Mater. 2011, 23, 1246-1253. (d) Crauste, C.; Périgaud, C.; Peyrottes, S. Synthesis of 2, 3'-Dideoxynucleoside Phosphoesters Using H-Phosphonate Chemistry on Soluble Polymer Support. J. Org. Chem. 2011, 76, 997-1000. (e) Dalvi, P. B.; Lin, S.-F.; Paike, V.; Sun, C.-M. Microwave-Assisted Multicomponent Synthesis of Dihydroquinoxalinones on Soluble Polymer Support. ACS Comb. Sci. 2015, 17, 421425.

(7) (a) Mayr, M.; Mayr, B.; Buchmeiser, M. R. Monolithic Materials: New High-performance Supports for Permanently Immobilized Metathesis Catalysts. Angew. Chem., Int. Ed. 2001, 40, 3839-3842. (b) Bandari, R.; Knolle, W.; Prager-Duschke, A.; Buchmeiser, M. R. Ring-Opening Metathesis Polymerization Based Post-Synthesis Functionalization of Electron Beam Curing Derived Monolithic Media. Macromol. Rapid Commun. 2007, 28, 2090-2094. (c) Anderson, E. B.; Buchmeiser, M. R. Catalysts Immobilized on Organic Polymeric Monolithic Supports: From Molecular Heterogeneous Catalysis to Biocatalysis. ChemCatChem 2012, 4, 30-41.

(8) (a) Curran, D. P. Parallel synthesis with fluorous reagents and reactants. Med. Res. Rev. 1999, 19, 432-438. (b) Curran, D. P. Organic Synthesis with Light-Fluorous Reagents, Reactants, Catalysts, and Scavengers. Aldrichimica Acta 2006, 39, 3-11. (c) Dandapani, S.; Curran, D. P. Second Generation Fluorous DEAD Reagents Have Expanded Scope in the Mitsunobu Reaction and Retain Convenient Separation Features. J. Org. Chem. 2004, 69, 8751-8757. (d) Zhang, W. Fluorous linker-facilitated chemical synthesis. Chem. Rev. 2009, 109, 749-795. (e) Sugiyama, Y.; Ishihara, K.; Masuda, Y.; Kobayashi, Y.; Hamamoto, H.; Matsugi, M. Fluorous mixture synthesis of fluorous-Fmoc reagents using a one-pot double tagging strategy. Tetrahedron Lett. 2013, 54, 2060-2062. (f) Kim, J.; Lee, W. S.; Koo, J.; Lee, J.; Park, S. B. Synthesis and Library Construction of Privileged Tetra-Substituted $\Delta^{5}$-2-Oxopiperazine as $\beta$-Turn Structure Mimetics. ACS Comb. Sci. 2014, 16, 24-32.

(9) (a) Guillier, F.; Orain, D.; Bradley, M. Linkers and cleavage strategies in solid-phase organic synthesis and combinatorial chemistry. Chem. Rev. 2000, 100, 2091-2157. (b) Polshettiwar, V.; Len, C.; Fihri, A. Silica-supported palladium: Sustainable catalysts for cross-coupling reactions. Coord. Chem. Rev. 2009, 253, 2599-2626. (c) Moreno, J.; Iglesias, J.; Melero, J. A.; Sherrington, D. C. Synthesis and characterisation of (hydroxypropyl)-2-aminomethyl pyridine containing hybrid polymer-silica SBA-15 materials supporting $\mathrm{Mo}(\mathrm{VI})$ centres and their use as heterogeneous catalysts for oct-1-ene epoxidation. J. Mater. Chem. 2011, 21, 6725-6735. (d) Fihri, A.; Bouhrara, M.; Patil, U.; Cha, D.; Saih, Y.; Polshettiwar, V. Fibrous nano-silica supported ruthenium (KCC-1/Ru): A sustainable catalyst for the hydrogenolysis of alkanes with good catalytic activity and lifetime. ACS Catal. 2012, 2, 1425-1431.

(10) (a) French, J. M.; Caras, C. A.; Diver, S. T. Removal of Ruthenium Using a Silica Gel Supported Reagent. Org. Lett. 2013, 15, 5416-5419. (b) Chepiga, K. M.; Feng, Y.; Brunelli, N. A.; Jones, C. W.; Davies, H. M. L. Silica-Immobilized Chiral Dirhodium(II) Catalyst for Enantioselective Carbenoid Reactions. Org. Lett. 2013, 15, 61366139. (c) Feng, Y.; Moschetta, E. G.; Jones, C. W. Polymer- and SilicaSupported Iron BPMEN-Inspired Catalysts for $\mathrm{C}-\mathrm{H}$ Bond Functionalization Reactions. Chem. - Asian J. 2014, 9, 3142-3152. (d) Long, W.; Jones, C. W. Hybrid Sulfonic Acid Catalysts Based on SilicaSupported Poly (Styrene Sulfonic Acid) Brush Materials and Their Application in Ester Hydrolysis. ACS Catal. 2011, 1, 674-681. (e) Conley, M. P.; Mougel, V.; Peryshkov, D. V.; Forrest, W. P.; Gajan, D. J.; Lesage, A.; Emsley, L.; Coperet, C.; Schrock, R. R. A WellDefined Silica-Supported Tungsten Oxo Alkylidene Is a Highly Active Alkene Metathesis Catalyst. J. Am. Chem. Soc. 2013, 135, 1906819070. (f) Mello, R.; Alcalde-Aragonés, A.; González-Núñez, M. E.; Asensio, G. Epoxidation of Olefins with a Silica-Supported Peracid in 
Supercritical Carbon Dioxide under Flow. J. Org. Chem. 2012, 77, 4706-4710.

(11) (a) Barrett, A. G. M.; Cramp, S. M.; Roberts, R. S. ROMPSpheres: A Novel High-Loading Polymer Support Using Cross Metathesis between Vinyl Polystyrene and Norbornene Derivatives. Org. Lett. 1999, 1, 1083-1086. (b) Barrett, A. G. M.; Hopkins, B. T.; Köbberling, J. ROMPgel Reagents in Parallel Synthesis. Chem. Rev. 2002, 102, 3301-3324. (c) Buchmeiser, M. R. Polymer-Supported Well-Defined Metathesis Catalysts. Chem. Rev. 2009, 109, 303-321. (d) Fuchter, M. J.; Hoffman, B. M.; Barrett, A. G. M. Ring-Opening Metathesis Polymer Sphere-Supported s eco-Porphyrazines: Efficient and Recyclable Photooxygenation Catalysts. J. Org. Chem. 2006, 71, 724-729. (e) Haque, H. A.; Kakehi, S.; Hara, M.; Nagano, S.; Seki, T. High-Density Liquid-Crystalline Azobenzene Polymer Brush Attained by Surface-Initiated Ring-Opening Metathesis Polymerization. Langmuir 2013, 29, 7571-7575.

(12) (a) Rolfe, A.; Loh, J. K.; Maity, P. K.; Hanson, P. R. High-Load, Hybrid Si-ROMP Reagents. Org. Lett. 2011, 13, 4-7. (b) Maity, P. K.; Rolfe, A.; Samarakoon, T. B.; Faisal, S.; Kurtz, R. D.; Long, T. R.; Schatz, A.; Flynn, D. L.; Grass, R. N.; Stark, W. J.; Reiser, O.; Hanson, P. R. Monomer-on-Monomer (MoM) Mitsunobu Reaction: Facile Purification Utilizing Surface-Initiated Sequestration. Org. Lett. 2011, 13, 8-10. (c) Maity, P. K.; Kainz, Q. M.; Faisal, S.; Rolfe, A.; Samarakoon, T. B.; Basha, F. Z.; Reiser, O.; Hanson, P. R. Intramolecular monomer-on-monomer (MoM) Mitsunobu cyclization for the synthesis of benzofused thiadiazepine-dioxides. Chem. Commun. 2011, 47, 12524-12526.

(13) (a) Maity, P. K.; Faisal, S.; Rolfe, A.; Stoianova, D.; Hanson, P. R. Silica-Supported Oligomeric Benzyl Phosphate (Si-OBP) and Triazole Phosphate (Si-OTP) Alkylating Reagents. J. Org. Chem. 2015, 80, 9942-9950. (b) Long, T.; Maity, P. K.; Samarakoon, T. B.; Hanson, P. R. ROMP-Derived Oligomeric Phosphates for Application in Facile Benzylation. Org. Lett. 2010, 12, 2904-2907. (c) Long, T. R.; Faisal, S.; Maity, P. K.; Rolfe, A.; Kurtz, R. D.; Klimberg, S. V.; Najjar, M. R.; Basha, F. Z.; Hanson, P. R. Click"-Capture, Ring-Opening Metathesis Polymerization (ROMP), Release: Facile Triazolation Utilizing ROMP-Derived Oligomeric Phosphates. Org. Lett. 2011, 13, 2038-2041.

(14) For additional benzylation reagents, see: (a) Crosignani, S.; White, P. D.; Linclau, B. Polymer-Supported O-Alkylisoureas: Useful Reagents for the O-Alkylation of Carboxylic Acids. J. Org. Chem. 2004, 69, 5897-5905. (b) Poon, K. W. C.; House, S. E.; Dudley, G. B. A Bench-Stable Organic Salt for Benzylation of Alcohols. Synlett 2005, 3142-3144. (c) Poon, K. W. C.; Dudley, G. B. Mix-and-Heat Benzylation of Alcohols Using a Bench-Stable Pyridinium Salt. J. Org. Chem. 2006, 71, 3923-3927 and references cited therein. (d) Zhang, M.; Flynn, D. L.; Hanson, P. R. Oligomeric Benzylsulfonium Salts: Facile Benzylation via High-Load ROMP Reagents. J. Org. Chem. 2007, 72, 3194-3198. (e) Lopez, S. S.; Dudley, G. B. Convenient method for preparing benzyl ethers and esters using 2-benzyloxypyridine. Beilstein J. Org. Chem. 2008, 4, No. 44.

(15) (a) René, O.; Fauber, B. P.; Malhotra, S.; Yajima, H. PalladiumCatalyzed $\alpha$-Arylation of Sultams with Aryl and Heteroaryl Iodides. Org. Lett. 2014, 16, 3468-3471. (b) Debnath, S.; Mondal, S. One-Pot Sonogashira Coupling-Cyclization toward Regioselective Synthesis of Benzosultams. J. Org. Chem. 2015, 80, 3940-3948. (c) Asad, N.; Samarakoon, T. B.; Zang, Q.; Loh, J. K.; Javed, S.; Hanson, P. R. Rapid, Scalable Assembly of Stereochemically Rich, Mono- and Bicyclic Acyl Sultams. Org. Lett. 2014, 16, 82-85. (d) Organ, M. G.; Hanson, P. R.; Rolfe, A.; Samarakoon, T. B.; Ullah, F. Accessing Stereochemically Rich Sultams via Microwave-Assisted, Continuous Flow Organic Synthesis (MACOS) Scale-out. J. Flow Chem. 2011, 1, 32-39. (e) Samarakoon, T. B.; Loh, J. K.; Rolfe, A.; Le, L. S.; Yoon, S. Y.; Lushington, G. H.; Hanson, P. R. A Modular Reaction Pairing Approach to the Diversity-Oriented Synthesis of Fused- and BridgedPolycyclic Sultams. Org. Lett. 2011, 13, 5148-5151. (f) JiménezHopkins, M.; Hanson, P. R. An RCM Strategy to Stereodiverse $\delta$ Sultam Scaffolds. Org. Lett. 2008, 10, 2223-2226. (g) Majumdar, K.
C.; Mondal, S. Recent Developments in the Synthesis of Fused Sultams. Chem. Rev. 2011, 111, 7749-7773.

(16) (a) Kim, S. H.; Ramu, R.; Kwon, S. W.; Lee, S. H.; Kim, C. H.; Kang, S. K.; Rhee, S. D.; Bae, M. A.; Ahn, S. H.; Ha, D. C.; Cheon, H. G.; Kim, K. Y.; Ahn, J. H. Discovery of cyclic sulfonamide derivatives as $11 \beta$-hydroxysteroid dehydrogenase 1 inhibitors. Bioorg. Med. Chem. Lett. 2010, 20, 1065-1069. (b) Supuran, C. T. Carbonic anhydrases: novel therapeutic applications for inhibitors and activators. Nat. Rev. Drug Discovery 2008, 7, 168-181. (c) Brzozowski, F.; Saczewski, F.; Neamati, N. Synthesis and anti-HIV-1 activity of a novel series of 1,4,2-benzodithiazine-dioxides. Bioorg. Med. Chem. Lett. 2006, 16, 5298-5302. (d) Silvestri, R.; Marfe, G.; Artico, M.; La Regina, G.; Lavecchia, A.; Novellino, E.; Morgante, M.; Di Stefano, C.; Catalano, G.; Filomeni, G.; Abruzzese, E.; Ciriolo, M. R.; Russo, M. A.; Amadori, S.; Cirilli, R.; La Torre, F.; Sinibaldi Salimei, P. Pyrrolo[1,2b] $[1,2,5]$ benzothiadiazepines (PBTDs): A New Class of Agents with High Apoptotic Activity in Chronic Myelogenous Leukemia K562 Cells and in Cells from Patients at Onset and Who Were ImatinibResistant. J. Med. Chem. 2006, 49, 5840-5844.

(17) Rocher, J.-P. Preparation of Diarylsultam Derivatives As Antipsychotic Agents. PCT Int. Appl. WO 9730038A1 19970821, 1997.

(18) Santora, V. J.; Covel, J. A.; Ibarra, J. B.; Semple, G.; Smith, B.; Smith, J.; Weinhouse, M. I.; Schultz, J. A. Biphenylsulfonamides as Modulators of the Histamine H3-Receptor Useful for the Treatment of Disorders Related Thereto and Their Preparation. PCT Int. Appl. WO 2008005338A1 20080110, 2008.

(19) McKerrecher, D.; Pike, K. G.; Waring, M. J. Preparation of Heteroaryl Benzamide Derivatives for Use As Glucokinase Activators in the Treatment of Type 2 Diabetes. PCT Int. Appl. WO 2006125972A1 20061130, 2006. (b) Campbell, L.; Pike, K. G.; Suleman, A.; Waring, M. J. Preparation of Benzoyl Amino Heterocyclyl Compounds as Glucokinase Activators for Treating Type 2 Diabetes and Other Dis-eases Mediated By GLK. PCT Int. Appl. WO 2008050101A2 20080502, 2008.

(20) Duan, J.; Chen, L.; Cherney, R. J.; Decicco, C. P.; Voss, M. E. W.O. Patent 1,994,126 Aug 19, 1988.

(21) (a) Faisal, S.; Ullah, F.; Maity, P. K.; Rolfe, A.; Samarakoon, T. B.; Porubsky, P.; Neuenswander, B.; Lushington, G. H.; Basha, F. Z.; Organ, M. G.; Hanson, P. R. Facile (Triazolyl)methylation of MACOS-derived Benzofused Sultams Utilizing ROMP-derived OTP Reagents. ACS Comb. Sci. 2012, 14, 268-272. (b) Rolfe, A.; Samarakoon, T. B.; Klimberg, S. V.; Brzozowski, M.; Neuenswander, B.; Lushington, G. H.; Hanson, P. R. S $S_{\mathrm{N}}$ Ar-Based, Facile Synthesis of a Library of Benzothiaoxazepine-1,1'-dioxides. J. Comb. Chem. 2010, 12, 850-854. (c) Rolfe, A.; Ullah, F.; Samarakoon, T. B.; Kurtz, R. D.; Porubsky, P.; Neunswander, B.; Lushington, G.; Santini, C.; Organ, M. G.; Hanson, P. R. Synthesis of Amino-Benzothiaoxazepine-1,1-dioxides Utilizing a Microwave-Assisted, $S_{N} A r$ Protocol. ACS Comb. Sci. 2011, 13, 653-658. (d) Loh, J. K.; Asad, N. A.; Samarakoon, T. B.; Hanson, P. R. Modular, One-Pot, Sequential Aziridine Ring Opening $-S_{N} A r$ Strategy to 7-,10-, and 11-Membered Benzo-Fused Sultams. J. Org. Chem. 2015, 80, 9926-9941.

(22) (a) Nguyen, S. T.; Johnson, L. K.; Grubbs, R. H.; Ziller, J. W. Ring-opening metathesis polymerization (ROMP) of norbornene by a Group VIII carbene complex in protic media. J. Am. Chem. Soc. 1992, 114, 3974-3975. (b) Schwab, P.; France, M. B.; Ziller, J. W.; Grubbs, R. H. A Series of Well-Defined Metathesis Catalysts-Synthesis of $\left[\mathrm{RuCl}_{2}\left(=\mathrm{CHR}^{\prime}\right)\left(\mathrm{PR}_{3}\right)_{2}\right]$ and Its Reactions. Angew. Chem., Int. Ed. Engl. 1995, 34, 2039-2041. (c) Schwab, P.; Grubbs, R. H.; Ziller, J. W. Synthesis and Applications of $\mathrm{RuCl}_{2}\left(=\mathrm{CHR}^{\prime}\right)\left(\mathrm{PR}_{3}\right)_{2}$ : The Influence of the Alkylidene Moiety on Metathesis Activity. J. Am. Chem. Soc. 1996, 118, 100-110. (d) Scholl, M.; Ding, S.; Lee, C. W.; Grubbs, R. H. Synthesis and Activity of a New Generation of Ruthenium-Based Olefin Metathesis Catalysts Coordinated with 1,3-Dimesityl-4,5dihydroimidazol-2-ylidene Ligands. Org. Lett. 1999, 1, 953-956. (e) Vougioukalakis, G. C.; Grubbs, R. H. Ruthenium-Based Heterocyclic Carbene-Coordinated Olefin Metathesis Catalysts. Chem. Rev. 2010, 110, 1746-1787. 
(23) (a) Cronin, S.; Chandrasekar, P. H. Safety of triazole antifungal drugs in patients with cancer. J. Antimicrob. Chemother. 2010, 65, 410416. (b) Nivoix, Y.; Ubeaud-Sequier, G.; Engel, P.; Leveque, D.; Herbrecht, R. Drug-drug interactions of triazole antifungal agents in multimorbid patients and implications for patient care. Curr. Drug Metab. 2009, 10, 395-409.

(24) Valverde, I. E.; Bauman, A.; Kluba, C. A.; Vomstein, S.; Walter, M. A.; Mindt, T. L. 1,2,3-Triazoles as Amide Bond Mimics: Triazole Scan Yields Protease-Resistant Peptidomimetics for Tumor Targeting. Angew. Chem., Int. Ed. 2013, 52, 8957-8960.

(25) It should be noted that the typical manner of installing a triazole group requires a two-step protocol, such as the alkylation of propargyl bromide (a severe lachrymator), followed by a click reaction with a corresponding azide. The developed Si-alkylating reagent avoids the use of these toxic reagents and provides a more modular way of installing a triazole group onto the complex-substrates in a one-pot protocol. Moreover, the developed Si-alkylating reagents are free flowing solids, bench stable and can be stored for longer time at room temperature and successfully utilized for alkylation reactions in a onepot protocol. In addition, once made they can be shipped under safer conditions as compared to the corresponding benzyl bromides. 